ADLFI. Archéologie de la France -

INFORMATIONS

Informations

une revue Gallia

Franche-Comté | 2001

\title{
Département du Doubs
}

Jean-Claude Mottaz

URL : http://journals.openedition.org/adlfi/8438

ISSN : 2114-0502

Éditeur

Ministère de la culture

Référence électronique

Jean-Claude Mottaz, "Département du Doubs », ADLFI. Archéologie de la France - Informations [En ligne], Franche-Comté, mis en ligne le 01 mars 2001, consulté le 19 avril 2019. URL : http://

journals.openedition.org/adlfi/8438

Ce document a été généré automatiquement le 19 avril 2019

(c) Ministère de la Culture et de la Communication, CNRS 


\title{
Département du Doubs
}

\author{
Jean-Claude Mottaz
}

Date de l'opération : 2001 (ME)

1 Les prospections de l'exercice 2001 ont été menées pour leur grande majorité sur le territoire de la commune de Clerval et aux alentours. Les pentes rocailleuses et boisées, entrecoupées de terrasses, qui entourent ce lieu de passage très fréquenté depuis la plus haute Antiquité, ont été soigneusement prospectées. Bien qu'aucune implantation n'y ait encore été décelée, l'importance et la variété du mobilier recueilli constituent des indices certains d'une fréquentation continue, voire permanente, au cours des siècles passés.

Quelques sites ont également été localisés dans les environs: une petite implantation gallo-romaine ainsi que deux sites ponctuels en relation avec la guerre de 1870. Conjointement, les recherches menées dans le secteur de Besançon-La Vèze ont permis la découverte de plusieurs sites gallo-romains, dont un d'importance. À ceci, il convient d'ajouter les prospections complémentaires après labours sur les sites déjà répertoriés, l'identification et la datation de sites répertoriés jusqu'alors indéterminés ainsi que l'intervention, à la demande d'archéologues, sur les chantiers de fouilles ou au cours de sondages.

\section{INDEX}

operation Prospection avec détecteur de métaux (ME)

Index géographique : Franche-Comté, Doubs (25), Clerval

Index chronologique : Antiquité, Empire romain, ép. contemporaine

Thèmes : datation, occupation du sol 
AUTEURS

JEAN-CLAUDE MOTTAZ

Bénévole 